\title{
Numerical model of particle deposition on fin surface of heat exchanger
}

\author{
Feilong Zhan, Dawei Zhuang, Guoliang Ding *, Jiajun Tang \\ (Institute of Refrigeration and Cryogenics, Shanghai Jiao Tong University, Shanghai 200240, China) \\ * Corresponding Author, Tel: 86-21-34206378; Fax: 86-21-34206814; E-mail: glding@ @jtu.edu.cn
}

\begin{abstract}
Dust particle deposition on fin surface has a significant influence on the performance of fin-and-tube heat exchangers, and the purpose of this study is to develop a numerical model for predicting the particle deposition rate on fin surface. In the model, the particle trajectories were calculated by the particle motion equation; the particle deposition on the fin surface was described based on the critical impact angle and the critical sticking velocity of incident particles; the particle deposition on the formed fouling layer was described based on the critical impact angle, the critical sticking velocity and the critical removal velocity of incident particles. The particle distributions on fin surface predicted by the model agree well with the images captured in the visualization experiment. The predicted particle deposition weight per unit area can describe $88 \%$ of the experimental data within a deviation of $\pm 20 \%$ and the mean deviation is $12.8 \%$.
\end{abstract}

Keywords: Heat exchanger; Particle deposition; Particle removal; Fin surface; Numerical model. 


\begin{tabular}{|c|c|c|c|}
\hline$A$ & area, $\mathrm{m}^{2}$ & $S$ & fin length, $\mathrm{mm}$ \\
\hline$c$ & particle mass flow rate, $\mathrm{kg} \mathrm{s}^{-1}$ & $v$ & velocity, $\mathrm{m} \mathrm{s}^{-1}$ \\
\hline$C_{\mathrm{D}}$ & drag coefficient & $v_{\mathrm{re} \_ \text {cri }}$ & critical removal velocity, $\mathrm{m} \mathrm{s}^{-1}$ \\
\hline$C_{\mathrm{L}}$ & lift coefficient & $v_{\text {st_cri }}$ & critical sticking velocity, $\mathrm{m} \mathrm{s}^{-1}$ \\
\hline$C_{\mathrm{m}}$ & proportionality factor & $w$ & weight of test sample, $\mathrm{kg}$ \\
\hline$d$ & diameter, $\mathrm{m}$ & $y$ & elastic load limit, $\mathrm{N}$ \\
\hline$d^{*}$ & effective diameter, $\mathrm{m}$ & & \\
\hline$E^{*}$ & equivalent Young's modulus, $\mathrm{N} \mathrm{m}^{-2}$ & Greek & \\
\hline$f$ & Darcy friction factor & $\alpha$ & inclination angle, radian \\
\hline$F$ & contact load, $\mathrm{N}$ & $\beta$ & effective coefficient of the contact radius \\
\hline$F_{\mathrm{A}}$ & adhesion force, $\mathrm{N}$ & $\theta$ & impact angle on a smooth surface, radian \\
\hline$F_{\mathrm{C}}$ & contact force, $\mathrm{N}$ & $\theta_{\mathrm{cr}}$ & critical impact angle, radian \\
\hline$F_{\mathrm{D}}$ & drag force, $\mathrm{N}$ & $\theta^{\prime}$ & impact angle on a rough surface, radian \\
\hline$F_{\mathrm{L}}$ & lift force, $\mathrm{N}$ & $\mu$ & fluid dynamic viscosity, $\mathrm{N} \mathrm{s} \mathrm{m}^{-2}$ \\
\hline$F P$ & fin pitch, $\mathrm{mm}$ & $\mu^{*}$ & effective friction coefficient \\
\hline$G^{*}$ & effective shear modulus, $\mathrm{N} \mathrm{m}^{-2}$ & $\rho$ & density, $\mathrm{kg} \mathrm{m}^{-3}$ \\
\hline$h$ & interpenetration distance of particle, $\mathrm{m}$ & $\zeta$ & surface energy, $\mathbf{J}$ \\
\hline$j$ & particle deposition weight per unit area, $\mathrm{kg} \mathrm{m}^{-2}$ & $\Delta v$ & velocity difference, $\mathrm{m} \mathrm{s}^{-1}$ \\
\hline$k_{\mathrm{C}}$ & coefficient of the contact force & $\Delta \gamma$ & standard deviation of impact angle, radian \\
\hline$k_{\theta}$ & coefficient of surface roughness & & \\
\hline$m$ & mass, $\mathrm{kg}$ & Subscript & \\
\hline$\dot{m}_{\mathrm{k}}$ & flow rate of the particle stream, $\mathrm{kg} \mathrm{s}^{-1}$ & adh & adhering particle \\
\hline$m^{*}$ & effective mass, $\mathrm{kg}$ & After & after particle injection \\
\hline$n$ & wall effect coefficient & Air & air side of test sample \\
\hline$N$ & number of particles & ave & average value \\
\hline$P_{\text {in }}$ & air-side pressure in the inlet, $\mathrm{Pa}$ & Before & before particle injection \\
\hline$P_{\text {out }}$ & air-side pressure in the outlet, $\mathrm{Pa}$ & el & limiting elastic status \\
\hline$P_{1}$ & longitudinal tube pitch, $\mathrm{mm}$ & face & surface of near-wall cell \\
\hline$P_{\mathrm{t}}$ & transverse tube pitch, mm & fouling & fouling layer \\
\hline$Q_{\mathrm{A}, \mathrm{a}}$ & surface adhesive energy, $\mathrm{J}$ & $\mathrm{g}$ & gas phase \\
\hline$Q_{\mathrm{A}, \mathrm{r}}$ & adhesion energy, J & $\mathrm{i}$ & incident status \\
\hline$Q_{\mathrm{el}}$ & limiting elastic energy, $\mathrm{J}$ & $\mathrm{i}, \mathrm{n}$ & normal direction in incident status \\
\hline$Q_{\text {in }}$ & normal component of kinetic energy, $\mathrm{J}$ & $\mathrm{i}, \mathrm{t}$ & tangential direction in incident status \\
\hline$Q_{\mathrm{p}}$ & energy loss due to plastic deformation, $\mathrm{J}$ & $\mathrm{p}$ & particle phase \\
\hline$Q_{\mathrm{pe}}$ & stored plastic deformation energy, J & $\mathrm{r}$ & rebound status \\
\hline$r$ & contact radius, $\mathrm{m}$ & $\mathrm{r}, \mathrm{n}$ & normal direction in rebound status \\
\hline$R_{\mathrm{c}}$ & curvature radius of particle, $\mathrm{m}$ & $\mathrm{r}, \mathrm{t}$ & tangential direction in rebound status \\
\hline$R_{\text {dep }}$ & critical deposition rate, $\mathrm{kg} \mathrm{m}^{-2} \mathrm{~s}$ & $\mathrm{t}$ & tube \\
\hline$R e_{\mathrm{p}}$ & particle Reynolds number & & \\
\hline
\end{tabular}




\section{Introduction}

Fin-and-tube heat exchanger is the most commonly used heat exchanger type in air-conditioning and refrigeration systems (Comini et al., 1995; Wang et al., 1997), and will be covered by particulate fouling after long-term operation. The effect of particulate fouling on the performance of heat exchangers depends on the particle deposition amount. Small quantity of particulate fouling may enhance the performance of heat exchangers because the slightly scattered particles adhering on fin surface may cause the air flow twisted and strengthen the interaction between vortexes and main flows (Pu et al., 2009). Deposition of abundant particles on fin surface after long-term operation will dramatically reduce the airflow area and increase the air-side thermal resistance, leading to a significant deterioration of the heat exchanger performance (Bell and Groll, 2011). It was found by Ahn et al. (2003) that the heat transfer capacity of fin-and-tube heat exchangers may decrease by $10 \sim 15 \%$ and the air-side pressure drop may increase by more than $44 \%$ after 7 years. In order to quantitatively know the effect of deposited particles and further to improve the long-term performance of fin-and-tube heat exchanger, a model for simulating the formation and development of particulate fouling is needed.

The formation and development of particulate fouling on fin surface are determined by the behaviors of particles as dusty air flows through heat exchangers. Under real operation conditions of air conditioners, the fluid on the air side of fin-and-tube heat exchanger is dusty air (Yang et al., 2007), and the particles in dusty air may be carried onto fin surface due to the air flow force (Liu et al., 2012). When the fin surface is bare, the impact between incident particles and fin surface occurs and the incident particles may either stick on or rebound from fin surface, leading to the formation of particulate fouling (Zhao and $\mathrm{Wu}, 2009$ ); when the fin surface has been covered by particulate fouling, the impact between incident particles and fouling layer occurs, and the deposition and removal of particles simultaneously exist during the fouling development process (Jeong et al., 2009). In order to simulate the formation and development of 
particulate fouling on heat exchanger, the model for describing the behaviors of particles, including particle transportation, particle-wall impact and particle-fouling layer impact, should be developed.

The existing researches on the simulation of particle transportation include the Euler approach and the Lagrangian approach, in which the particles are regarded as continuous phase and discrete phase, respectively. For the Euler approach, the particles are tracked by solving the averaged conservation equations of particles in the similar format to the gas phase (Jackson, 1997; Hu et al., 2001); and this approach is suitable for the occasion with dense suspended particles because the particle-particle interactions cannot be neglected and the particle motions may influence the gas flow field (Mashayek and Pandya, 2003; Wachem et al., 2001; Zhao and Chen, 2006). For the Lagrangian approach, the particles are tracked by solving the particle force balance equations, in which the particle forces may include drag force, gravity, thermophoresis, Saffman lift force and so on (Timmer and Zeller, 2004); and this approach is suitable for the occasion with sparse particles because the particle-particle interactions can be ignored and the particles have no feedback effects on the gas flow field (Zhang and Chen, 2009; Romay et al., 1998). In this paper, the Lagrangian approach was adopted in the model of particle transportation because the particle concentration in outdoor air is dilute enough and the diameters of deposited particles on heat exchanger are small enough to not influence the gas flow field (Ahn and Lee, 2005).

The existing researches on simulating the particle-wall impact focus on the particle deposition characteristics on wall surface by assuming the wall surface as a smooth wall surface or a pre-fouled wall surface. For the smooth wall surface, the particle deposition rate resulted from the particle-wall impact can be obtained by the probability statistics (Lee et al., 2002; Huang et al., 1996; Venturini et al., 2012) and the semi-empirical correlations (Siegel and Nazaroff, 2003; Paz et al., 2013; Leppänen et al., 2014). In the probability statistics, the particle deposition rate is considered as a function of impact efficiency and sticking probability by dimensionless analysis. In the semi-empirical correlations, the 
quantitative effects of each influencing factor on particle deposition rate are obtained by theoretical analysis or experimental investigation; thus the semi-empirical correlations for calculating the particle deposition rate can be obtained by combining these individual influencing factors. For the pre-fouled wall surface, the physical properties of wall are replaced by fouling layer (Thornton and Ning, 1998; Beek et al., 2006; Jiang et al., 2010), and the impact behaviors of incident particles are described by three parameters, including the proportionality factor, the restitution coefficient, and the friction coefficient (Konstandopoulos, 2006; Abd-Elhady et al., 2006); however, the roughness of fouling layer has not been taken into consideration.

The existing researches on simulating the particle-fouling layer impact only focus on the deposition of incident particles or the removal of bed particles. For the deposition of incident particles, the incident particles may either stick on or rebound from fouling layer, which is similar to that in particle-wall impact process (Pan et al., 2011). For the removal of bed particles, the bed particles may either keep still or remove from fouling layer, and the behaviors of bed particles are determined by the incident particle impact and the influence of air flow. In the incident particle impact, the behaviors of bed particles can be described by the force propagation characteristics due to the loose and porous structure of fouling layer (Abd-Elhady et al., 2004; Rodriguez and Smith, 2007; Han et al., 2014). In the influence of air flow, the drag force and lift force acting on the bed particles may make the bed particles separate from fouling layer (Abd-Elhady et al., 2008; Polley et al., 2002; Mu et al., 2012).

The integrated particle deposition process to describe the formation and development of particulate fouling on heat exchanger should both cover the particle-wall impact type and the particle-fouling layer impact type, and simultaneously reflect the deposition of incident particles and the removal of bed particles. For the impact type, Jiang et al. (2010) proposed a particle-wall impact model for predicting the deposition velocity by assuming the wall surface as a bare wall surface constituted with different materials; Abd-Elhady et al. (2006) employed the discrete element method 
to simulate the interaction between a particle hitting a bed of particles by assuming the wall surface as a pre-fouled wall surface. However, the impact type should be switched from the particle-wall impact to the particle-fouling layer impact when a fouling layer has formed on fin surface, which cannot be described by the models developed in the existing researches. For the deposition of incident particles and the removal of bed particles, Han et al. (2014) developed a numerical model to predict the flue-ash particle deposition rate without considering the process of particle removal; Mu et al. (2012) also developed a numerical deposition model to predict the ash deposition characteristics, and the effect of particle removal was neglected. However, in the development of particulate fouling on fin surface, both the sticking criterions and removal criterions should be established for the incident particles and bed particles respectively, which cannot be described by the existing models.

The purpose of the present study is to propose an integrated particle deposition model for simulating the particle behaviors on fin surface of heat exchanger, including particle transportation, particle-wall impact and particle-fouling layer impact. Moreover, a visual experiment is performed to validate the proposed model.

\section{Numerical model}

\subsection{Technical road map}

A fin-and-tube heat exchanger may be severely fouled by particle deposition after long-term operation, as shown in Fig. 1(a). The deposited particles mostly accumulate on the fin surface because the fin takes a large part of air-side area of heat exchanger, as shown in Fig. 1(b). The particle deposition process consists of three parts. Firstly, the particles are carried onto the fin surface due to transport mechanisms such as inertial impact, Brownian movement and turbulent diffusion, as shown in Fig. 1(c); secondly, the particles in the air impact with fin surface and potentially deposit on it, leading to the formation of particulate fouling, as shown in Fig. 1(d); thirdly, the particles in the air impact with fouling 
layer which consists of bed particles, and may make the bed particles remove from fin surface, leading to the development of particulate fouling, as shown in Fig. 1(e). Therefore, the particle behaviors during the deposition process consist of particle transportation, particle-wall impact and particle-fouling layer impact in sequence.

The particle transportation characteristics can be described by the motion trajectories of incident particles, which are determined by velocities of particles in flow field between fins, as shown in Fig. 1(c). At the beginning, the incident particles with no velocity are taken into the flow field by air flow. Then, the particles with different Stokes number will present different trajectories (Van, 2001). The incident particles with small Stokes number may follow the airflow to escape from the target surface (i.e., the fin surface or the fouling layer surface); while the incident particles with large Stokes number may transport to the target surface, and only these particles have opportunity to impact and deposit on the target surface. Therefore, the key for predicting particle transportation characteristics is to establish the model of particle transportation for obtaining the velocities of incident particles.

The particle-wall impact process can be divided into the incident particles sticking on fin surface and the incident particles rebounding from fin surface, which are determined by the critical impact angle and the critical sticking velocity, as shown in Fig. 1(d). If the impact angle of incident particle is smaller than the critical impact angle and the impact velocity is smaller than the critical sticking velocity, the incident particle will stick on fin surface; while if the impact angle of incident particle is larger than the critical impact angle or the impact velocity is larger than the critical sticking velocity, the incident particle will rebound from fin surface (Konstandopoulos, 2006). Once the fin surface is covered by a fouling layer, the succeeding incident particles will impact with the fouling layer. Therefore, the key for predicting the particle behaviors on fin surface is to establish the model of particle-wall impact for obtaining the sticking criterions of incident particles and the transformation criterion of impact types.

The particle-fouling layer impact process can be classified into the sticking of incident particles and the removing 
of bed particles. The sticking of incident particles is determined by the critical impact angle and the critical sticking velocity, and the removing of bed particles is determined by the critical removal velocity, as shown in Fig. 1(e). For the incident particles, if the impact angle is smaller than the critical impact angle and the impact velocity is smaller than the critical sticking velocity, the incident particle will stick on the fouling layer; while if the impact angle is larger than the critical impact angle or the impact velocity is larger than the critical sticking velocity, the incident particle will rebound from the fouling layer. For the bed particles, if the impact velocity is smaller than the critical removal velocity, the bed particle will keep still on the fouling layer; while if the impact velocity is larger than the critical removal velocity, the bed particle will remove from the fouling layer. Therefore, the key for predicting the particle behaviors on fouling layer is to establish the model of particle-fouling layer impact for obtaining the sticking criterions of incident particles and the removal criterions of bed particles.

The technical road map of particle deposition model is demonstrated in Fig. 2. Firstly, the velocities of incident particles are obtained by the model of particle transportation, and the particle trajectories can be obtained to determine whether the incident particles are carried onto the target surface (i.e., the fin surface or the fouling layer surface) or not. Then, the particle-wall impact model and the particle-fouling layer impact model are developed for calculating the critical impact angle, the critical sticking velocity and the critical removal velocity, which are compared with the impact angle and the impact velocity of incident particles to determine the behaviors of incident particles and bed particles. Finally, the particle deposition rate on heat exchanger can be obtained by counting the number of deposited particles and the number of removed particles.

\subsection{Model of particle transportation}

The schematic diagram of particle transportation is shown in Fig. 3, and the trajectories of incident particles are 
dominantly influenced by the air flow.

The motion trajectories of incident particles are calculated by integrating the force balance on particles. For the dust particles in outdoor circumstance, the drag force is at least one order of magnitude higher than other forces, especially for big particles (Han et al., 2014). Thus, only the effect of drag force on the particle trajectory was considered, and the particle motion equation can be given as Eq. (1):

$$
\frac{d \vec{v}_{\mathrm{p}}}{d t}=F_{\mathrm{D}}\left(\vec{v}_{\mathrm{g}}-\vec{v}_{\mathrm{p}}\right)
$$

where $v_{\mathrm{p}}$ is the particle velocity, $v_{\mathrm{g}}$ is the gas velocity, and $F_{\mathrm{D}}$ is the drag force action on the particle which can be expressed as Eq. (2):

$$
F_{\mathrm{D}}=\frac{3 \mu C_{\mathrm{D}} R e_{\mathrm{p}}}{4 \rho_{\mathrm{p}} d_{\mathrm{p}}^{2}}
$$

where $d_{\mathrm{p}}$ is particle diameter, $\rho_{\mathrm{p}}$ is the particle density, $\mu$ is the fluid dynamic viscosity, $C_{\mathrm{D}}$ is the drag coefficient, and $R e_{\mathrm{p}}$ is particle Reynolds number which can be defined as Eq. (3):

$$
R e_{\mathrm{p}}=\frac{\rho_{\mathrm{g}}\left|\vec{v}_{\mathrm{g}}-\vec{v}_{\mathrm{p}}\right| d_{\mathrm{p}}}{\mu}
$$

The drag coefficient $C_{\mathrm{D}}$ in Eq. (2) is unknown, and can be determined by the particle Reynolds number. For the fin-and-tube heat exchangers used in outdoor unit, the particle Reynolds number is always lower than 1000 (Wachem et al., 2001). Thus, the drag coefficient can be expressed by the Shiller-Naumann relation (Wachem et al., 2001), as shown in Eq. (4):

$$
C_{\mathrm{D}}= \begin{cases}\frac{24}{R e_{\mathrm{p}}}, & R e_{\mathrm{p}}<1 \\ 24 \frac{\left(1+0.15 R e_{\mathrm{p}}^{0.687}\right)}{R e_{\mathrm{p}}}, & 1<R e_{\mathrm{p}}<1000\end{cases}
$$




\subsection{Model of particle-wall impact}

\subsubsection{Sticking criterions of incident particles}

The formation of particulate fouling on fin surface is schematically shown in Fig. 4(a). The sticking criterions of incident particles can be described by energy balance during the particle deformation process (as shown in Fig. 4(b)), and can be decomposed into the normal sticking criterion and the tangential sticking criterion. The particle deformation includes elastic deformation, limiting elastic deformation and elastic-plastic deformation in sequence, as shown in Figs. 4(c) - 4(e) respectively, and are determined by the interpenetration distance of particle $h$, the contact radius $r$ and the contact load $F$.

(1) Normal sticking criterion

The normal sticking criterion is used to determine the degree of energy loss and calculate the normal rebound velocity if particle rebound occurs. The energy conversation equations in the normal impact process can be expressed as Eqs. (5) and (6) (Van, 2001):

$$
\begin{gathered}
Q_{\mathrm{in}}+Q_{\mathrm{A}, \mathrm{a}}(F)=Q_{\mathrm{el}}+Q_{\mathrm{pe}}(F)+Q_{\mathrm{p}}(F) \\
Q_{\mathrm{in}}=\frac{1}{2} m_{\mathrm{p}} v_{\mathrm{i}, \mathrm{n}}^{2} \\
Q_{\mathrm{A}, \mathrm{a}}(F)=\zeta \pi\left(r_{\mathrm{el}}^{2}+\frac{F-F_{\mathrm{el}}}{\pi y}\right) \\
Q_{\mathrm{el}}=\frac{\pi^{5} d_{\mathrm{p}}^{3} y^{5}}{480 E^{* 4}} \\
Q_{\mathrm{pe}}(F)=\frac{1}{2} h_{\mathrm{el}}\left(F-F_{\mathrm{el}}\right) \\
Q_{\mathrm{p}}(F)=\frac{\left(F-F_{\mathrm{el}}\right)^{2}}{4 \pi d_{\mathrm{p}} y}
\end{gathered}
$$

where $m_{\mathrm{p}}$ is the mass of incident particle, $Q_{\mathrm{in}}$ is the normal component of kinetic energy of the incident particle, $Q_{\mathrm{A}, \mathrm{a}}$ is the surface adhesive energy due to the attractive forces between the incident particle and fin surface, $Q_{\mathrm{el}}$ is the limiting 
elastic energy, $Q_{\mathrm{pe}}$ is the stored plastic deformation energy, $Q_{\mathrm{p}}$ is the energy loss due to plastic deformation, $\zeta$ is surface energy, $E^{*}$ is the equivalent Young's modulus, $y$ is the elastic load limit, $r_{\mathrm{el}}, F_{\mathrm{el}}$, and $h_{\mathrm{el}}$ are the contact radius, the contact load and the interpenetration distance of particle under the limiting elastic deformation respectively. The contact load $F$ is the only unknown variable and can be obtained by solving Eqs. (5) and (6).

The key for establishing the normal sticking criterion is to determine whether the stored elastic energy $Q_{\mathrm{el}}$ and $Q_{\mathrm{pe}}$ during the contact are lower than the adhesion energy $Q_{\mathrm{A}, \mathrm{r}}$, which the incident particle should overcome in order to separate from the fin surface (Han et al., 2014; Van, 2001). Thus the sticking condition can be shown in Eq. (7):

$$
Q_{\mathrm{el}}+Q_{\mathrm{pe}} \leq Q_{\mathrm{A}, \mathrm{r}}=Q_{\mathrm{A} . \mathrm{a}}+10.41 r^{4}\left(\frac{E^{* 2} \zeta^{5}}{F^{4}}\right)^{1 / 3}
$$

Substituting Eq. (5) into Eq. (7), the critical sticking velocity can be obtained as:

$$
v_{\text {st_cri }}=\sqrt{\frac{Q_{\text {A.r }}-Q_{\text {A.a }}+Q_{\mathrm{p}}}{1 / 2 m_{\mathrm{p}}}}
$$

Then in the case of a rebound, the normal rebound velocity can be calculated by combining Eqs. (5) - (7), as shown in Eq. (9).

$$
v_{\mathrm{r}, \mathrm{n}}=\sqrt{\frac{Q_{\mathrm{in}}-Q_{\mathrm{p}}-\left(Q_{\mathrm{A} . \mathrm{r}}-Q_{\mathrm{A} . \mathrm{a}}\right)}{1 / 2 m_{\mathrm{p}}}}
$$

(2) Tangential sticking criterion

The tangential sticking criterion is used to determine the motion state of particle and calculate the tangential rebound velocity if particle rebound occurs. A critical impact angle $\theta_{\mathrm{cr}}$ is defined to describe the tangential sticking criterion that the incident particle will rebound from fin surface if the impact angle $\theta$ is larger than the critical impact angle $\theta_{\text {cr }}$ (Konstandopoulos, 2006). The estimate of critical impact angle $\theta_{\text {cr }}$ is resulted from the energy balance between the tangential kinetic energy of particle and the minimum energy required to break the contact (Pan et al., 
2011), as shown in Eqs. (10) and (11):

$$
\begin{gathered}
\tan \theta_{\mathrm{cr}}=\frac{\mu^{*}}{\left(32 \beta^{3}\right)^{1 / 2}} \sqrt{\frac{E^{*}}{G^{*}}} \\
\beta=\frac{4 r^{3}}{3 F}\left(\frac{9 \pi \zeta d_{\mathrm{p}}^{2}}{E^{* 4}}\right)^{-1 / 3}
\end{gathered}
$$

where $\mu^{*}$ is the effective friction coefficient, $G^{*}$ is the effective shear modulus of particle-granules, and $\beta$ is the effective coefficient of contact radius.

Then in the case of a rebound, the tangential rebound velocity can be calculated by integrating force balance on tangential direction (Thornton and Ning, 1998), as shown in Eq. (12).

$$
\vec{v}_{\mathrm{r}, \mathrm{t}}=\vec{v}_{\mathrm{i}, \mathrm{t}}-\mu^{*}\left(1+\frac{\left|\vec{v}_{\mathrm{r}, \mathrm{n}}\right|}{\left|\vec{v}_{\mathrm{i}, \mathrm{n}}\right|}\right) \frac{C_{\mathrm{m}}}{1+C_{\mathrm{m}}} \frac{\left|\vec{v}_{\mathrm{i}, \mathrm{n}}\right|}{\left|\vec{v}_{\mathrm{i}, \mathrm{t}}\right|} \vec{v}_{\mathrm{i}, \mathrm{t}}
$$

where $C_{\mathrm{m}}$ is the proportionality factor.

Based on the above equations, the sticking criterion of incident particles in the model of particle-wall impact can be described as:

(1) If $\theta>\theta_{\mathrm{cr}}$, or if $\theta<\theta_{\mathrm{cr}}$ and $v_{\mathrm{i}, \mathrm{n}}>v_{\mathrm{st} \_ \text {cri, }}$, the incident particle rebounds from the fin surface;

(2) If $\theta<\theta_{\text {cr }}$ and $v_{\mathrm{i}, \mathrm{n}} \leq v_{\mathrm{st} \_ \text {cri }}$, the incident particle sticks on the fin surface.

\subsubsection{Transformation criterion for impact type}

The transformation criterion for switching the impact type from particle-wall impact to particle-fouling layer impact is obtained by defining a critical deposition rate on the near-wall cell, as shown in Eq. (13):

$$
R_{\mathrm{dep}}=\sum_{\mathrm{k}=1}^{N} \frac{\dot{m}_{\mathrm{k}}}{A_{\text {face }}}
$$

where $R_{\text {dep }}$ is the critical deposition rate, $A_{\text {face }}$ is the area of near-wall cell, $N$ is the number of particles when the 
near-wall cell is filled with particles, $\dot{m}_{\mathrm{k}}$ is the flow rate of particle stream as it hits the surface.

\subsection{Model of particle-fouling layer impact}

\subsubsection{Sticking criterions of incident particles}

The development of particulate fouling is schematically shown in Fig. 5(a), including the deposition of incident particles and the removal of bed particles, as shown in Fig. 5(b).

The sticking criterions of incident particles in the particle-fouling layer impact process are similar to those in the particle-wall impact process, except that the physical properties of incident particles as well as the expression of impact angle should be modified (Heinl and Bohnet, 2005; Sommerfeld and Huber, 1999). The mass and diameter of incident particle should be replaced by an effective mass and an effective diameter in order to equivalently describe the particle-fouling layer impact process as the particle-wall impact process; meanwhile the impact angle should take the roughness of fouling layer into consideration.

The effective mass $m^{*}$ and the effective diameter $d^{*}$ can be described by Eqs. (14) and (15):

$$
\begin{gathered}
m^{*}=\frac{m_{\mathrm{p}} m_{\text {fouling }}}{m_{\mathrm{p}}+m_{\text {fouling }}} \\
d^{*}=\frac{d_{\mathrm{p}} d_{\text {fouling }}}{d_{\mathrm{p}}+d_{\text {fouling }}}
\end{gathered}
$$

where $m_{\text {fouling }}$ and $d_{\text {fouling }}$ are the mass and diameter of fouling layer respectively.

The impact angle $\theta^{\prime}$ comprises of the initial impact angle between particle and smooth surface as well as a stochastic contribution due to the wall roughness (Pan et al., 2011; Heinl and Bohnet, 2005), and can be defined as Eqs. (16) and (17):

$$
\theta^{\prime}=\theta+\Delta \gamma
$$




$$
\Delta \gamma=k_{\theta}\left(\frac{\pi}{2}-\arccos \left(\frac{d_{\mathrm{adh}}}{d_{\mathrm{adh}}+d_{\mathrm{p}}}\right)\right)
$$

where $\Delta \gamma$ is a standard deviation of impact angle due to the surface roughness, $k_{\theta}$ is the coefficient of surface roughness, and the value ranges from $1 / 6$ to $0.5, d_{\text {adh }}$ is the diameter of adhering particles.

\subsubsection{Removal criterions of bed particles}

The removal criterions of bed particles for obtaining the critical removal velocity are determined by the force balance equation shown in Fig. 5(c), as expressed in Eq. (18):

$$
\vec{F}_{\mathrm{L}}+\vec{F}_{\mathrm{C}}+\vec{F}_{\mathrm{D}}+\vec{F}_{\mathrm{A}}=0
$$

where $F_{\mathrm{L}}$ is the lift force, $F_{\mathrm{C}}$ is the contact force, $F_{\mathrm{D}}$ is the drag force, $F_{\mathrm{A}}$ is the adhesion force. The forces acting on a bed particle deposited on the porous fouling layer can be divided into two categories. The first category results from the effect of air flow, including the lift force and the drag force. The second category results from the effect of fouling layer, including the contact force and the adhesion force.

The lift force $F_{\mathrm{L}}$ acting on a bed particle is generated as a result of velocity gradient in the stagnant fluid region among the porous deposited fouling layer, and can be obtained by the Saffman's lift force formula (Ramadan et al., 2003), as shown in Eqs. (19) and (20):

$$
\begin{gathered}
F_{\mathrm{L}}=\frac{\pi}{8} C_{\mathrm{L}} d_{\mathrm{p}}^{2} v_{\mathrm{g}}^{2} \rho_{\mathrm{g}} \\
C_{\mathrm{L}}=4.11\left(\frac{d_{\mathrm{p}}}{v_{\mathrm{g}} \operatorname{Re} e_{\mathrm{P}}} \frac{d v_{\mathrm{g}}}{d n}\right)^{0.5}
\end{gathered}
$$

where $C_{\mathrm{L}}$ is the lift coefficient.

The contact force $F_{\mathrm{C}}$ acting on a bed particle will be mostly transferred along the strong force chains in the fouling layer (Abd-Elhady et al., 2008). Thus, the ultimate contact force can be written as Eqs. (21) and (22): 


$$
\begin{gathered}
F_{\mathrm{C}}=k_{\mathrm{C}} h^{1.5} \\
k_{\mathrm{C}}=\frac{4}{3} E^{*}\left(0.5 d^{*}\right)^{\frac{1}{2}}
\end{gathered}
$$

where $k_{\mathrm{c}}$ is the coefficient of contact force and it depends on the dynamic wave propagation of fouling layer, $h$ is the interpenetration distance in the elastic-plastic impact process, as shown in Fig. 4.

The drag force $F_{\mathrm{D}}$ acting on a bed particle should take the effect of wall and the velocity distribution near the wall into consideration (Rabinovich and Kalman, 2009), as shown in Eqs. (23) and (24):

$$
\begin{gathered}
F_{\mathrm{D}}=n \frac{\pi}{8} C_{\mathrm{D}} \rho d_{\mathrm{p}}^{2}\left(v_{\mathrm{g}}-v_{\mathrm{p}}\right)^{2} \\
n=5.3-3.6 e^{-0.0015 R e_{\mathrm{p}}}
\end{gathered}
$$

where $n$ is the coefficient of wall effect.

The adhesion force $F_{\mathrm{A}}$ acting on a bed particle is mainly resulted from the adhesion energy among the inter-particles of fouling layer (Rogers and Reed, 1984), and can be expressed as Eq. (25) (Abd-Elhady et al., 2006):

$$
F_{\mathrm{A}}=1.5 \pi R_{\mathrm{c}} \zeta
$$

where $R_{\mathrm{c}}$ is the curvature radius in the particle deformation shown in Fig. 4, and can be described by Thornton et al. (1998) and Johnson et al. (1971).

The equation to calculate the critical removal velocity is deduced by combing Eqs. (18) - (25). Taking the force conditions shown in Fig. 5(c) for example, the force balance equation to calculate the critical removal velocity yields to Eq. (26):

$$
F_{\mathrm{L}} \cos \alpha+F_{\mathrm{C}} \cos \theta^{\prime}-F_{\mathrm{A}}-F_{\mathrm{D}} \sin \alpha=0
$$

where $\alpha$ is the inclination angle of fin.

Substituting Eqs. (18) - (25) into Eq. (26), a critical removal velocity can be obtained as:

$$
v_{\text {re_cri }}=f\left(\Delta v, \alpha, \theta^{\prime}, R e_{\mathrm{p}}\right)
$$


It can be concluded from Eq. (27) that, the critical removal velocity $v_{\text {re_cri }}$ is a function of the velocity difference $\Delta v$ between air flow and incident particles, the impact position $\alpha$, the impact angle $\theta^{\prime}$ and the particle Reynolds number $R e_{\mathrm{p}}$.

\subsubsection{Integrated criterions of particle deposition}

Based on the above sticking criterions and removal criterions, the integrated criterions of particle deposition in the model of particle-fouling layer impact can be described as:

(1) If $\theta^{\prime}>\theta_{\mathrm{cr}}$, or if $\theta^{\prime}<\theta_{\mathrm{cr}}$ and $v_{\mathrm{i}, \mathrm{n}}>v_{\mathrm{st} \_ \text {cri }}$, the incident particle rebounds from the fouling layer;

(2) If $\theta^{\prime}<\theta_{\text {cr }}$ and $v_{\mathrm{i}, \mathrm{n}} \leq v_{\mathrm{st} \_ \text {cri }}$, the incident particle sticks on the fouling layer;

(3) If $v_{\mathrm{i}, \mathrm{n}}>v_{\text {re_cri, }}$, the bed particle removes from the fouling layer.

\section{Simulation case}

\subsection{Simulation domain and grid independency}

The simulation domain and computational grids of a wavy fin-and-tube heat exchanger are shown in Fig. 6 . The boundary condition settings in the simulation domain shown in Fig. 6(a) are required as follows. For the inlet surface, the constant inlet velocity of air flow and particle injection were given. For the outlet surface, an outflow boundary condition was adopted. A symmetric boundary condition was adopted for the front and back surfaces, and a periodic boundary condition was adopted for the upper and lower surfaces. The no-slip boundary conditions were given for the solid surfaces.

The average Darcy friction factor $f$ is employed to validate the independency of fluid-field grid, which is defined 
by Eq. (28) (Gong et al., 2013):

$$
f=\frac{2\left(\bar{p}_{\text {in }}-\bar{p}_{\text {out }}\right)}{\rho_{\mathrm{g}} v_{\text {ave }}^{2}} \cdot \frac{d_{\mathrm{t}}}{S}
$$

where $p_{\text {in }}$ and $p_{\text {out }}$ are the air-side pressure in the inlet and outlet respectively, $d_{\mathrm{t}}$ is the tube diameter, and $S$ is the fin length.

For the boundary layer on the fin surface, the grid size was chosen as $0.001 \mathrm{~mm}$ in order to allow the growth of surface elements representing the fouling layer. For the flow field between fins, the grid sizes were chosen as $0.3 \mathrm{~mm}$, $0.2 \mathrm{~mm}, 0.1 \mathrm{~mm}, 0.08 \mathrm{~mm}$ and $0.06 \mathrm{~mm}$ in sequence to validate the grid independency. It was found that, the variation of the average Darcy friction factor $f$ under air velocity of $3 \mathrm{~m} / \mathrm{s}$ is smaller than $1 \%$ as the grid size decreases from $0.08 \mathrm{~mm}$ to $0.06 \mathrm{~mm}$. Thus, the size of fluid-field grid with $0.08 \mathrm{~mm}$ is considered to be fine enough to resolve the flow characteristics in all simulations.

\subsection{Validation of fluid flow computational model and solution settings}

The RNG $k-\varepsilon$ turbulent model was employed to deal with the effect of turbulence on the flow-field in the present paper. To compare the computational and experimental results, the identical geometric parameters presented by Wang et al. (2002) were adopted in the present paper. The Reynolds number ranges from 524 to 1,573, which corresponds to the frontal air velocity range of $1-3 \mathrm{~m} / \mathrm{s}$. The maximum deviation for $f$ was less than $7.9 \%$ and the average deviation was around 5.8\%, as shown in Fig. 7. Thus, the agreement between the simulation results and experimental results indicated that the fluid flow computational model was reliable.

As for the solution settings about the description of particle deposition process, all the models developed above were employed through user-defined functions (UDFs). The particle transport model was implemented as a drag law in 
the injection properties. The particle-wall impact model and the particle-fouling layer impact model were both implemented as deposition boundary conditions on the fin surface. The calculation of deposition rate was implemented as a supplement to the macro function of DEFINE_DPM_EROSION, and the display of deposition thickness was implemented as an execution function of UDM.

The particle injection type in the present paper was the surface type that particles would enter into the flow field through the inlet surface. The continuous phase was simulated in unsteady condition with fluid time step of $0.1 \mathrm{~s}$, and the discrete phase was simulated with particle time step of $0.01 \mathrm{~s}$. Thus, particles would inject 10 times during a fluid flow time step. The $\mathrm{SiO}_{2}$ was adopted as the particle in the present paper, and the detailed particle properties (Konstandopoulos, 2006; Van, 2001) are tabulated in Table 1.

\subsection{Display method of particle deposition thickness}

The particle deposition thickness on the fin surface, as shown in Fig. 8(a) and Fig. 8(b), should be displayed in order to conveniently investigate the particle deposition characteristics. A User Defined Memory (UDM) method was developed in the present study for displaying the simulated deposition thickness, as shown in Fig. 8(c). In this method, the UDM value of a flow-field cell is assigned as 0 means that this cell is not occupied by fouling layer, while the UDM value is assigned as 1 means that this cell is occupied by fouling layer. For the cell with UDM=1, the value of cell viscosity was set to infinity. Thus, the fluid cell could be converted into a solid cell, and the boundary surface around this cell could be converted into the reflecting surface or the deposited surface. 


\section{Experimental validations and results}

\subsection{Experimental rig and data reduction}

The validation of the proposed model in the present study should include two parts: 1) the qualitative validation of particle distribution; 2) the quantitive validation of particle deposition rate. For qualitatively validating the distribution of particles, the images of particle deposition process on the test sample will be captured by the camera in this study; for quantitively validating the model, the experimental data of particle deposition weight will also be obtained.

The images of particle deposition process and the experimental data of particle deposition weight were obtained by a visualization experimental rig (Zhan et al., 2016), which includes a wind tunnel system, a dust generation system, a transparent test section and a weighing system, as shown in Fig. 9. The wavy fin-and-tube heat exchangers with different fin pitches were chosen as the test samples for validating model, and the geometric parameters are shown in

Table 2.

The parameter of particle deposition weight per unit area $j$ is used to validate the model, and was deduced by measuring the weight of test sample, as expressed in Eq. (29):

$$
j=\frac{w_{\text {after }}-w_{\text {before }}}{A_{\text {air }}}
$$

where $w_{\text {before }}$ is the weight of test sample before particle injection, $w_{\text {after }}$ is the weight of test sample after particle injection, and $A_{\text {air }}$ is the air side area of test sample.

The uncertainty of the particle deposition weight per unit area was obtained by the analysis method proposed by Moffat (1988), and the maximum uncertainty of $j$ was calculated as $\pm 3.4 \%$. 


\subsection{Fluid flow characteristics and particle field distribution}

Particle deposition is affected not only by the particle-wall impact or particle-fouling layer impact, but also by the fluid flow characteristics. Figure 10 shows both the velocity contour and particle field distribution between wavy fins with $v=2 \mathrm{~m} / \mathrm{s}$ and $d_{\mathrm{p}}=50 \mu \mathrm{m}$. For the velocity contour, it can be seen that the periodic interruption of boundary layer growth and the periodic streamline deflection were generated as the air flow passed through the fins because of the wavy corrugation, which is also obtained by Jang et al. (1997). Thus, flow recirculation regions can be observed on wavy troughs and air velocities were quite small in these regions, resulting in an enhanced possibility of particle deposition on wavy troughs. Besides, less flow recirculation regions can be observed on wavy crests because of the repeated interruption of the flow, causing a great proportion of particles rebound from the wavy crests. For the particle field distribution, it can be seen that most particles followed the air flow and impacted with the wavy fin, and the rebounded particles would return to the air flow again until them deposit on or escape from the fin surface.

\subsection{Validation of model in predicting particle distributions}

In order to obtain the good agreement between simulation results and experimental results, the particle diameters in the experiments are limited in a small range and close to those in simulations. In the experiments, the particles diameters were ranging from $48 \mu \mathrm{m}$ to $53 \mu \mathrm{m}$ because these particles were filtered by vibrating screen with mesh number of 270 and 300 in order; while in the simulations, the particle diameter was $50 \mu \mathrm{m}$.

Figure 11 shows the comparison of particle deposition thickness on fin surface between simulation results and experimental results at fin pitch $F P=1.5 \mathrm{~mm}$, air velocity $v=1.5 \mathrm{~m} \mathrm{~s}^{-1}$, particle mass flow rate $c=0.001 \mathrm{~kg} \mathrm{~s}^{-1}$ and the injection time of $60 \mathrm{~min}$. The particle mass flow rate was calculated through the particle concentration multiplying by air volume flow rate, and the air volume flow rate is calculated by air inlet velocity and windward area. In 2D model, 
the windward area is equal to the product of the length of inlet and unit length. The images of particle deposition process were recorded on the top view of test sample and the time nodes were chosen as the 10th minute, the 30th minute and the 60th minute respectively.

From Fig. 11, it can be seen that the predicted particle distributions, including the shapes of particulate fouling and the deposition thickness, agree well with those of experimental images. The comparison of particle distributions between predicted and experimental result in the 10th minute is shown in Fig. 11(a). It can be seen that the deposition thicknesses on fin surface was nearly uniform, and the particle deposition amount in the experimental result was a little more than that in the predicted result. The slight difference may be mainly resulted from the surface status of fins. In the simulation, the fin surface is considered as smooth; while in the experiment, the fin surface is not completely smooth, leading to more particles stick on the fin surface.

The comparison of particle distributions between predicted and experimental result in the 30th minute is shown in Fig. 11(b). It can be seen that the deposition thicknesses on fin surface became thicker and the quantity of deposited particles on the trough of way fin was more than that on the other fin locations. The possible reason for this phenomenon is that, a fluid stagnation region would form in the trough of wavy, in which the vortices weaken the effect of airflow, causing that the deposited particles are not easy to remove from the fouling layer. The slight difference between the predicted particulate fouling shape and the experimental image may be mainly caused by the inaccurate description of the porosity of fouling layer.

The comparison of particle distribution between predicted and experimental result in the 60th minute is shown in Fig. 11(c). It can be seen that the deposition thickness increased further and the quantity of deposited particles on the trough of wavy fin increased dramatically; meanwhile, the particle deposition amount in the experiment result was more than that in the predicted result. The difference of particle deposition amount may be mainly resulted from the gravity. 
In the simulation, the gravity of particles was neglected because the magnitude of gravity is far less than the magnitude of drag force; while in the experiment, large particulate lump would be affected by the gravity, resulting in partial deposited particles dropping out from the fouling layer.

\subsection{Comparisons of particle deposition rate between predicted and experimental results}

Figure 12 shows the comparisons of particle deposition rate between the predicted and experimental results. The predicted results under the effects of fin pitch, air velocity and particle mass flow rate agree well with the experimental results, and the maximum deviations between predicted and experimental results are $15 \%, 11 \%$ and $32 \%$ respectively, as shown in Fig. 12(a) 12(c).

From Fig. 12(a), it can be seen that small fin pitch is beneficial to particle deposition and the particle deposition rate decreased by $-63.1 \%$ with the increase of fin pith from 1.2 to $1.8 \mathrm{~mm}$. The possible explanation is that, with the increase of fin pitch, the impact area decreases under the same channel cross-sectional area, causing less impact possibility between particles and fin surface.

From Fig. 12(b), it can be seen that low air velocity is prone to particle deposition, while high air velocity restrains particle deposition. The possible reasons for this phenomenon are shown as follows. Firstly, the kinetic energy of the incident particles increases with the increase of air velocity, resulting in more inclination to break away from the fluid and impact with the fin surface. Secondly, further increased air velocity intensifies the removal of the bed particles, and the adhesive energy is insufficient to absorb the incident particles, leading to the decrease of particle deposition rate.

From Fig. 12(c), it can be seen that high particle mass flow rate can dramatically promote particle deposition. The reason for this phenomenon is that high particle mass flow rate can increase impact frequency, resulting in an enhanced 
possibility of deposition.

The difference between predicted and experimental results is mainly resulted from the gravity and the surface status of fins, and can be explained as follows. Firstly, in the simulation, the gravity is neglected; while in the experiment, the gravity may impel the deposited fouling lump on the top of fouling layer to separate from the fouling layer with the increase of deposition thickness. Secondly, the fin surface is assumed as smooth in the simulation, while a little oil or some other impurities may retain on the fin surface in the experiment.

\subsection{Validation of model in predicting particle deposition weight per unit area}

Figure 13 shows the comparison of particle deposition weight per unit area between the simulation results and experimental data at $F P=1.2 \sim 1.8 \mathrm{~mm}, v=0.5 \sim 4.0 \mathrm{~m} \mathrm{~s}^{-1}, c=0.0001 \sim 0.01 \mathrm{~kg} \mathrm{~s}^{-1}$ and the injection time of $0 \sim 60$ min. It can be seen that the predicted results agree well with the experimental data. The predicted results can describe $88 \%$ of the experimental data within the deviation limit of $\pm 20 \%$ and the mean deviation is $12.8 \%$.

\section{Conclusions}

1) The particle deposition process includes particle transportation, particle-wall impact and particle-fouling layer impact, and the particle deposition rate on fin surface can be predicted by the integrated numerical model which comprises the sub-models of these three processes.

2) The sub-model of particle transportation can be developed by introducing particle motion equations on the particles, which can be calculated by integrating force balance on the particles.

3) The sub-model of particle-wall impact can be developed by establishing the sticking criterions of incident particles and the transformation criterion of impact type. 
4) The sub-model of particle-fouling layer impact can be developed by establishing the sticking criterions of incident particles and the removal criterions of bed particles on the fouling layer.

5) The simulation results of particle distributions on the fin surface agreed well with the experimental results, and the predicted particle deposition weight per unit area can describe $88 \%$ of the experimental data within the deviation limit of $\pm 20 \%$ and the mean deviation is $12.8 \%$.

\section{Acknowledgements}

The authors gratefully acknowledge the support from the Foundation for Innovative Research Groups of the National Natural Science Foundation of China (Grant No. 51521004) and the Program of Shanghai Academic Research Leader (Grant No. 16XD1401500).

\section{References}

Abd-Elhady, M.S., Rindt, C.C.M, Wijers, J.G., Steenhoven, A.A.V., Bramer, E.A., Meer, T.H., 2004. Minimum gas speed in heat exchangers to avoid particulate fouling. Int. J. Heat Mass Transfer. 47(17), 3943-3955.

Abd-Elhady, M.S., Rindt, C.C.M., Wijers, J.G., Steenhoven, A.A.V., 2006. Modelling the impaction of a micron particle with a powdery layer. Powder Technol. 168(3), 111-124.

Abd-Elhady, M.S., Rindt, C.C.M., Steenhoven, A.A.V., 2008. Contact time of an incident particle hitting a 2D bed of particles. Powder Technol. 191(3), 315-326.

Ahn, Y.C., Cho, J.M., Shin, H.S., Hwang, Y.J., Lee, C.G., Lee, J.K., Lee, H.U., Kang, T.W., 2003. An experimental study of the air-side particulate fouling in fin-and-tube heat exchangers of air conditioners. Korean J. Chem. Eng. 
$20(5), 873-877$.

Ahn, Y.C., Lee, J.K., 2005. Characteristics of air-side particulate fouling materials in finned-tube heat exchangers of air conditioners. Part. Sci. Technol. 23(3), 297-307.

Beek, M.C.V., Rindt, C.C.M., Wijers, J.G., Steenhoven, A.A.V., 2006. Rebound characteristics for 50- $\mu \mathrm{m}$ particles impacting a powdery deposit. Powder Technol. 165(2), 53-64.

Bell, I.H., Groll, E. A., 2011. Air-side particulate fouling of microchannel heat exchangers: Experimental comparison of air-side pressure drop and heat transfer with plate-fin heat exchanger. Appl. Therm. Eng. 31(5), 742-749.

Chen, Y.S., Hsiau, S.S., 2009. Cake formation and growth in cake filtration. Powder Technol. 192(2), 217-224.

Comini, G., Corteila, G., Saro, O., 1995. Finite element analysis of coupled conduction and convection in refrigerated transport. Int. J. Refrig. 18(2), 123-131.

Gong, J.Y., Min, C.H., Qi, C.Y., Wang, E.Y., Tian, L.T., 2013. Numerical simulation of flow and heat transfer characteristics in wavy fin-and-tube heat exchanger with combined longitudinal vortex generators. Int. Commun. Heat Mass Transfer. 43(2), 53-56.

Han, H., He, Y.L., Tao, W.Q., Li, Y.S., 2014. A parameter study of tube bundle heat exchangers for fouling rate reduction. Int. J. Heat Mass Transfer. 72(3), 210-221.

Heinl, E., Bohnet, M., 2005. Calculation of particle--wall adhesion in horizontal gas-solids flow using CFD. Powder Technol. 159(2), 95-104.

Hu, H.H., Patankar, N.A., Zhu, M.Y., 2001. Direct numerical simulations of fluid-solid systems using the arbitrary Lagrangian-Eulerian technique. J. Comput. Phys. 169(2), 427-462.

Huang, L.Y., Norman, J.S., Pourkashanian, M., Williams, A., 1996. Prediction of ash deposition on superheater tubes from pulverized coal combustion. Fuel. 75(3), 271-279. 
Jackson, R., 1997. Locally averaged equations of motion for a mixture of identical spherical particles and a Newtonian fluid. Chem. Eng. Sci. 52(52), 2457-2469.

Jang, J.Y., Chen, L.K., 1997. Numerical analysis of heat transfer and fluid flow in a three-dimensional wavy-fin and tube heat exchanger. Int. J. Heat Mass Transfer. 40(16), 3981-3990.

Jeong, J.W., Bem, J., Bahnfleth, W.P., Freihaut, J.D., Thran, B., 2009. Critical review of aerosol particle transport models for building HVAC ducts. J. Archit. Eng. 15(3), 74-83.

Jiang, H., Lu, L., Sun, K., 2010. Simulation of particle deposition in ventilation duct with a particle-wall impact model. Build. Environ. 45(5), 1184-1191.

Johnson, K.L., Kendall, K., Roberts, A.D., 1971. Surface energy and the contact of elastic solids. Proc. R. Soc. A. 324(1558), 301-313.

Konstandopoulos, A.G., 2006. Particle sticking/rebound criteria at oblique impact. J. Aerosol Sci. 37(3), $292-305$.

Lee, B.E., Fletcher, C.A.J., Shin, S.H., Kwon, S.B., 2002. Computational study of fouling deposit due to surface-coated particles in coal-fired power utility boilers. Fuel. 81(15), 2001-2008.

Leppänen, A., Tran, H., Taipale, R., Valimaki, E., Oksanen, A., 2014. Numerical modeling of fine particle and deposit formation in a recovery boiler. Fuel. 129(7), 45-53.

Liu, D., Zhao, F.Y., Wang, H.Q., Rank, E., 2012. Turbulent transport of airborne pollutants in a residential room with a novel air conditioning unit. Int. J. Refrig. 35(5), 1455-1472.

Mashayek, F., Pandya, R.V.R., 2003. Analytical description of particle/droplet-laden turbulent flows. Prog. Energ. Combust. 29(4), 329-378.

Moffat, R.J., 1988. Describing the uncertainties in experimental results. Exp. Therm. Fluid Sci. 1(1), 3-17.

Mu, L., Zhao, L., Yin, H., 2012. Modelling and measurements of the characteristics of ash deposition and distribution in 
a HRSG of wastewater incineration plant. Appl. Therm. Eng. 44(6), 57-68.

Pan, Y., Si, F., Xu, Z., Romero, C.E., 2011. An integrated theoretical fouling model for convective heating surfaces in coal-fired boilers. Powder Technol. 210(2), 150-156.

Paz, C., Suárez, E., Eirís, A., Porteiro, J., 2013. Development of a predictive CFD fouling model for diesel engine exhaust gas systems. Heat Transfer Eng. 34(8), 674-682.

Polley, G.T., Wilson, D.I., Yeap, B.L., Pugh, S.J., 2002. Evaluation of laboratory crude oil threshold fouling data for application to refinery pre-heat trains. Appl. Therm. Eng. 22(7), 777-788.

Pu, H., Ding, G.L., Ma, X.K., Hu, H.T., Gao, Y.F., 2009. Effects of biofouling on air-side heat transfer and pressure drop for finned tube heat exchangers. Int. J. Refrig. 32(5), 1032-1040.

Rabinovich, E., Kalman, H., 2009. Incipient motion of individual particles in horizontal particle-fluid systems: B. Theoretical analysis. Powder Technol. 192(3), 326-338.

Ramadan, A., Skalle, P., Johansen, S.T., 2003. A mechanistic model to determine the critical flow velocity required to initiate the movement of spherical bed particles in inclined channels. Chem. Eng. Sci. 58(10), 2153-2163.

Rodriguez, C., Smith, R., 2007. Optimization of operating conditions for mitigating fouling in heat exchanger networks. Chem. Eng. Res. Des. 85(6), 839-851.

Rogers, L.N., Reed, J., 1984. The adhesion of particles undergoing an elastic-plastic impact with a surface. J. Phys. D: Appl. Phys. 17(4), 677-689.

Romay, F.J., Takagaki, S.S., Pui, D.Y.H., Liu, B.Y.H., 1998. Thermophoretic deposition of aerosol particles in turbulent pipe flow. J. Aerosol Sci. 29(98), 943-959.

Siegel, J.A., Nazaroff, W.W., 2003. Predicting particle deposition on HVAC heat exchangers. Atmos. Environ. 37(39), 5587-5596. 
Sommerfeld, M., Huber, N., 1999. Experimental analysis and modelling of particle-wall collisions. Int. J. Multiphase Flow. 25(6), 1457-1489.

Thornton, C., Ning, Z., 1998. A theoretical model for the stick/bounce behaviour of adhesive, elastic-plastic spheres. Powder Technol. 99(2), 154-162.

Timmer, H., Zeller, M., 2004. Particle deposition near ceiling induction outlets. Int. J. Refrig. 27(3), 248-254.

Van, B.M.C., 2001. Gas-side fouling in heat-recovery boilers. Eindhoven University of Technology, The Netherlands.

Venturini, P., Borello, D., Hanjalić, K., Rispoli, F., 2012. Modelling of particles deposition in an environment relevant to solid fuel boilers. Appl. Therm. Eng. 49(1), 131-138.

Wachem, B.G.M.V., Schaaf, J.V.D., Schouten, J.C., Krishna, R., Bleek, C.M.V.D., 2001. Experimental validation of Lagrangian-Eulerian simulations of fluidized beds. Powder Technol. 116(2), 155-165.

Wang, C.C., Fu, W.L., Chang, C.T., 1997. Heat transfer and friction characteristics of typical wavy fin-and-tube heat exchangers. Exp. Therm. Fluid. Sci. 14(2), 174-186.

Wang, C.C., Hwang, Y.M., Lin, Y.T., 2002. Empirical correlations for heat transfer and flow friction characteristics of herringbone wavy fin-and-tube heat exchangers. Int. J. Refrig. 25(5), 673-680.

Yang, L., Braun, J.E., Groll, E.A., 2007. The impact of fouling on the performance of filter-evaporator combinations. Int. J. Refrig. 30(3), 489-498.

Zhan, F.L., Tang, J.J., Ding, G.L., Zhuang, D.W., 2016. Experimental investigation on particle deposition characteristics of wavy fin-and-tube heat exchangers. Appl. Therm. Eng. 99, 1039-1047.

Zhang, Z., Chen, Q., 2009. Prediction of particle deposition onto indoor surfaces by CFD with a modified Lagrangian method. Atmos. Environ. 43(2), 319-328.

Zhao, B., Chen, J.J., 2006. Numerical analysis of particle deposition in ventilation duct. Build. Environ. 41(6), 710-718. 
Zhao, B., Wu, J., 2009. Modeling particle fate in ventilation system—Part I: model development. Build. Environ. 44(3), $605-611$. 


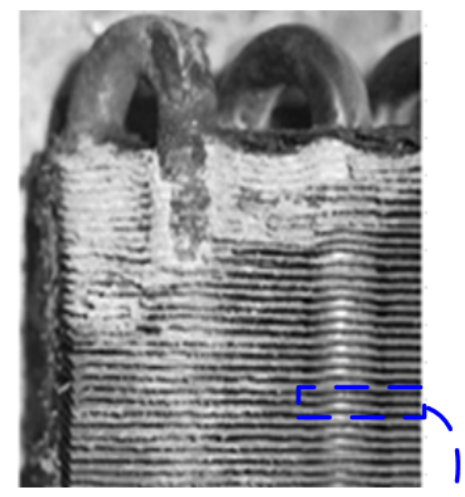

(a) Fouling on a fin-and- / tube heat exchanger

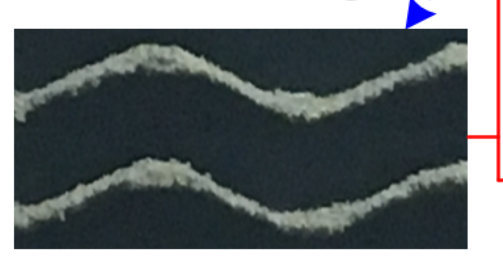

(b) Fouling on the fin surfaces

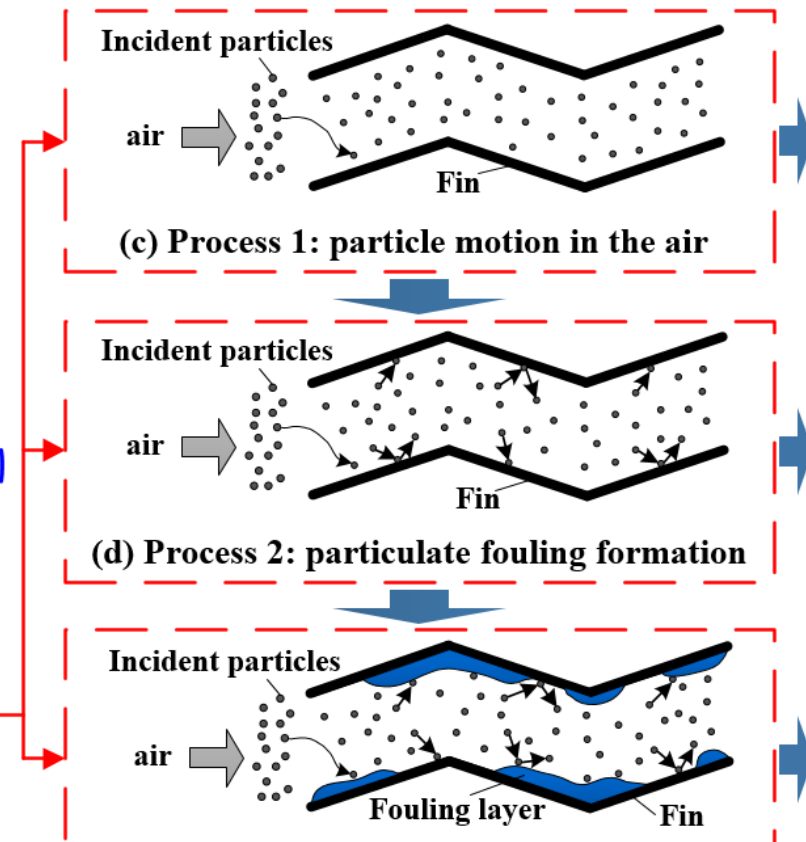

(e) Process 3: particulate fouling development
Particle

transportation

Fig. 1. Schematic diagram of particle behaviors during deposition process in heat exchanger. 


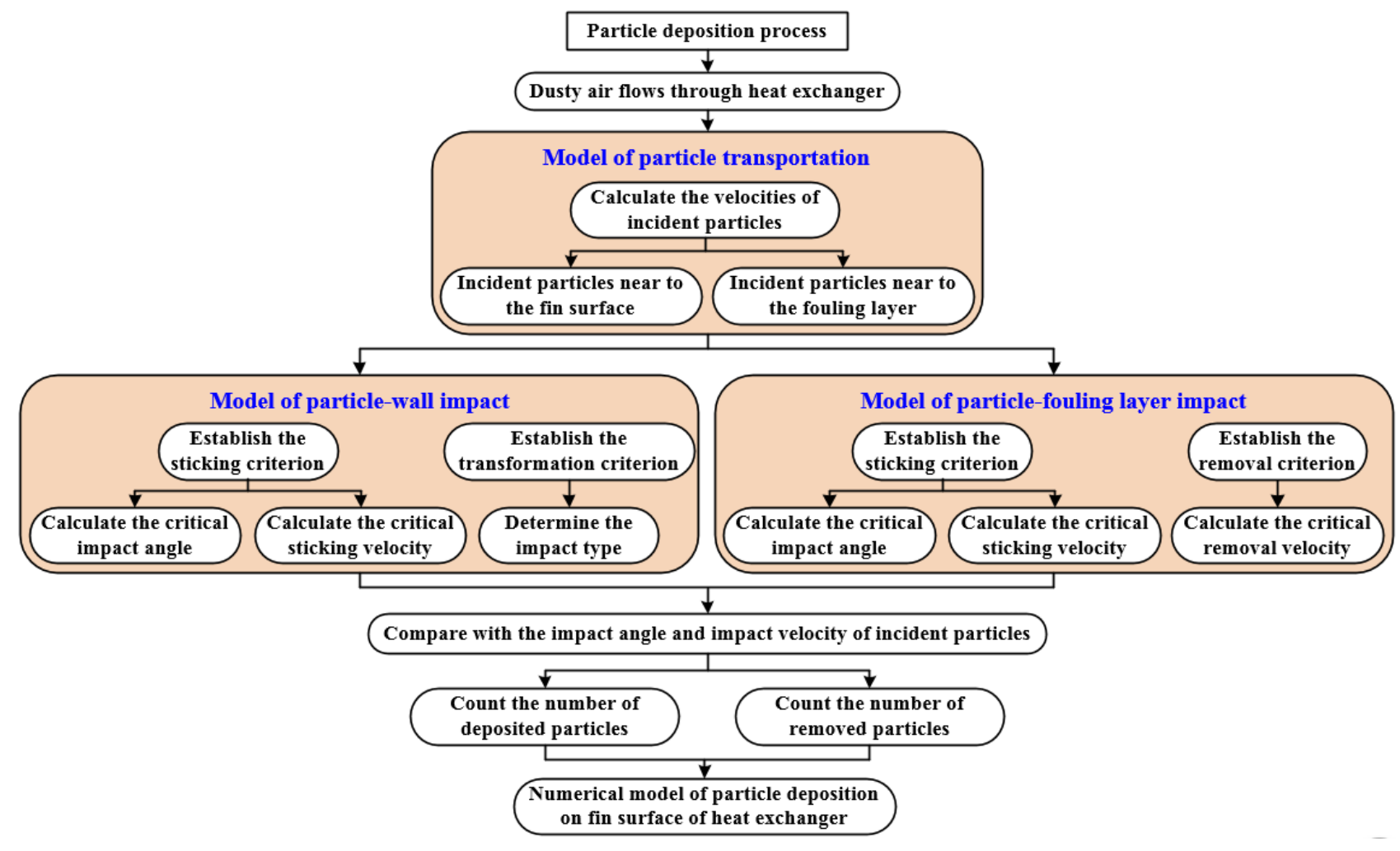

Fig. 2. Technical road map for particle deposition model. 


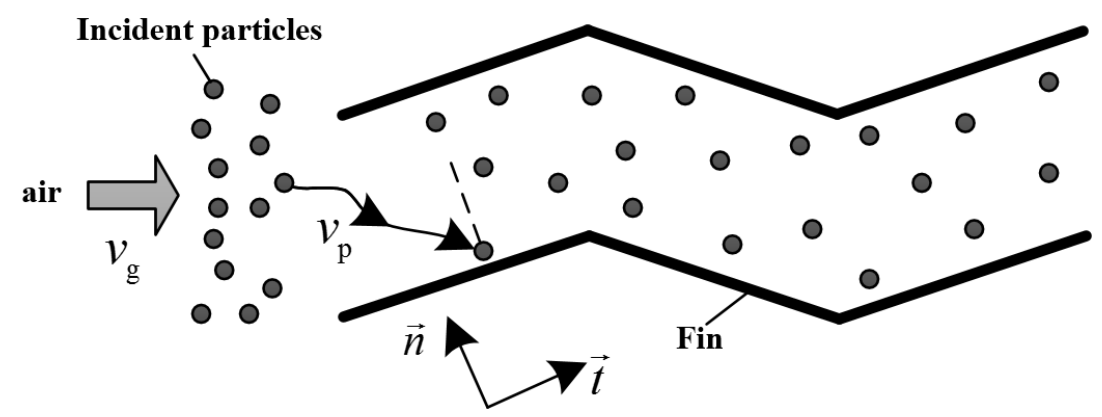

Fig. 3. Schematic diagram of particle transportation. 


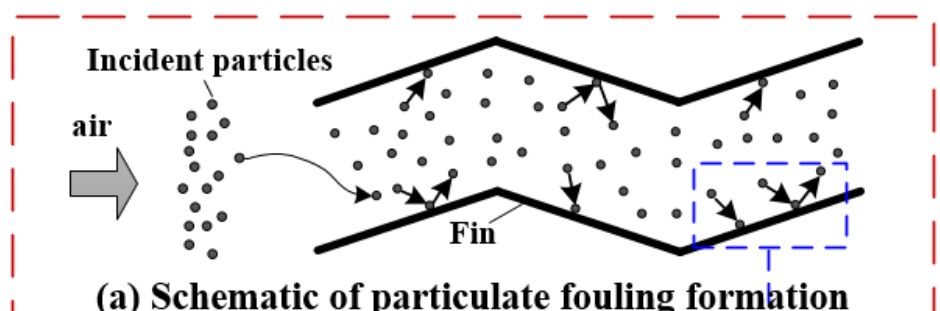

(a) Schematic of particulate fouling formation

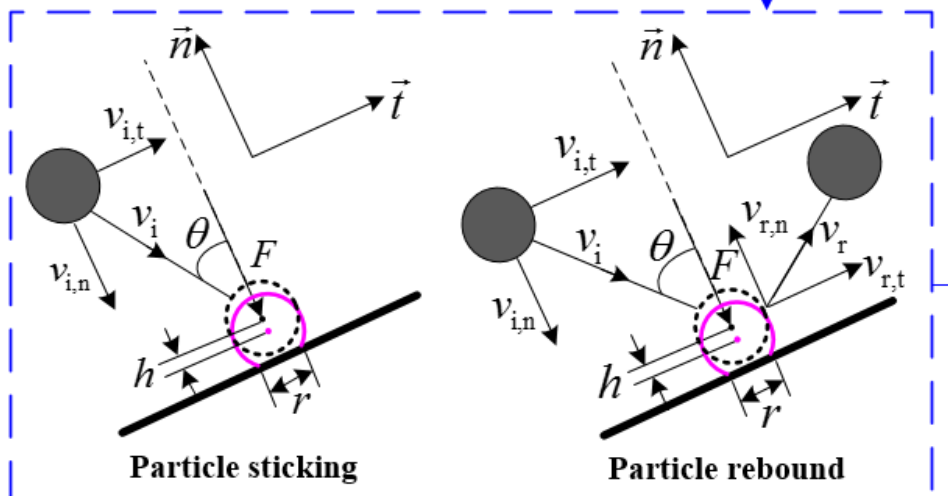

(b) Particle deformation during the impact process

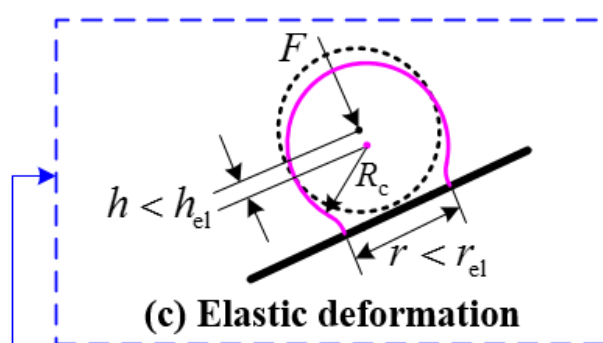

(c) Elastic deformation

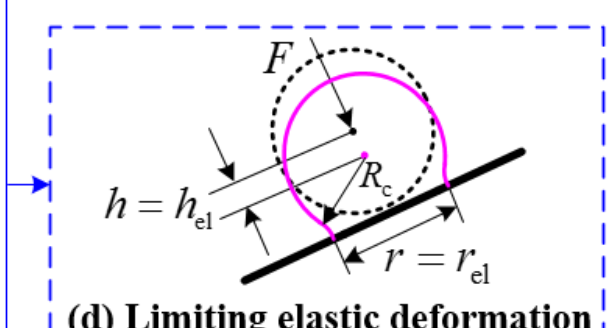

(d) Limiting elastic deformation

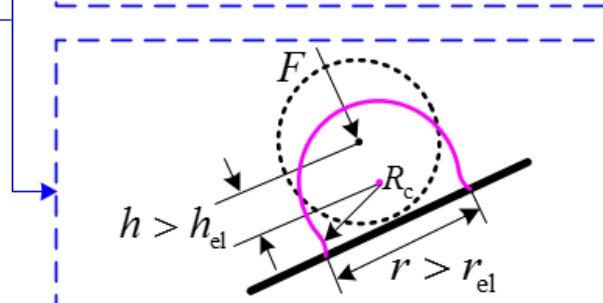

(e) Elastic-plastic deformation

Fig. 4. Schematic diagram of impact process between particle and fin surface. 


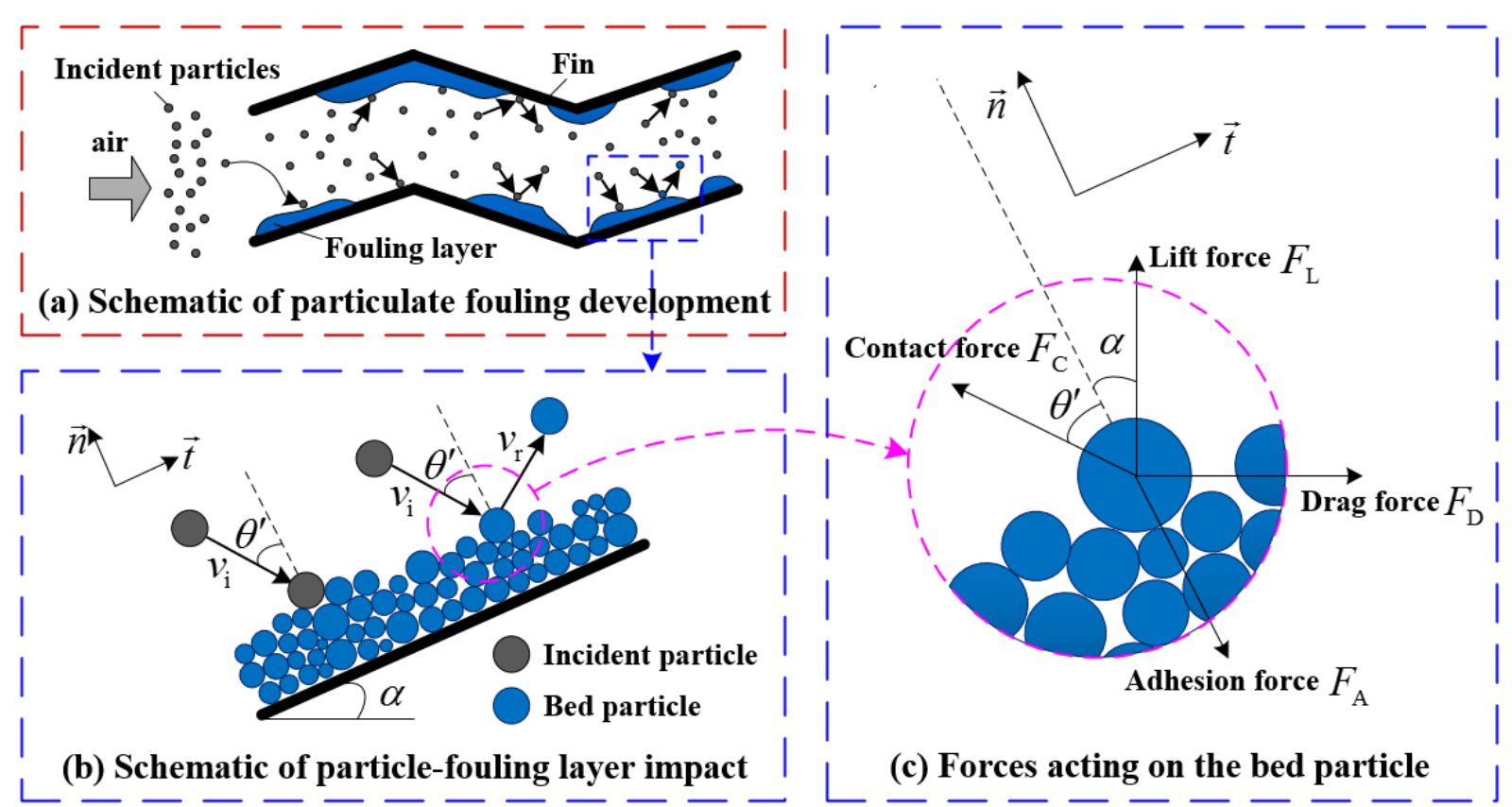

Fig. 5. Schematic diagram of impact process between particle and fouling layer. 


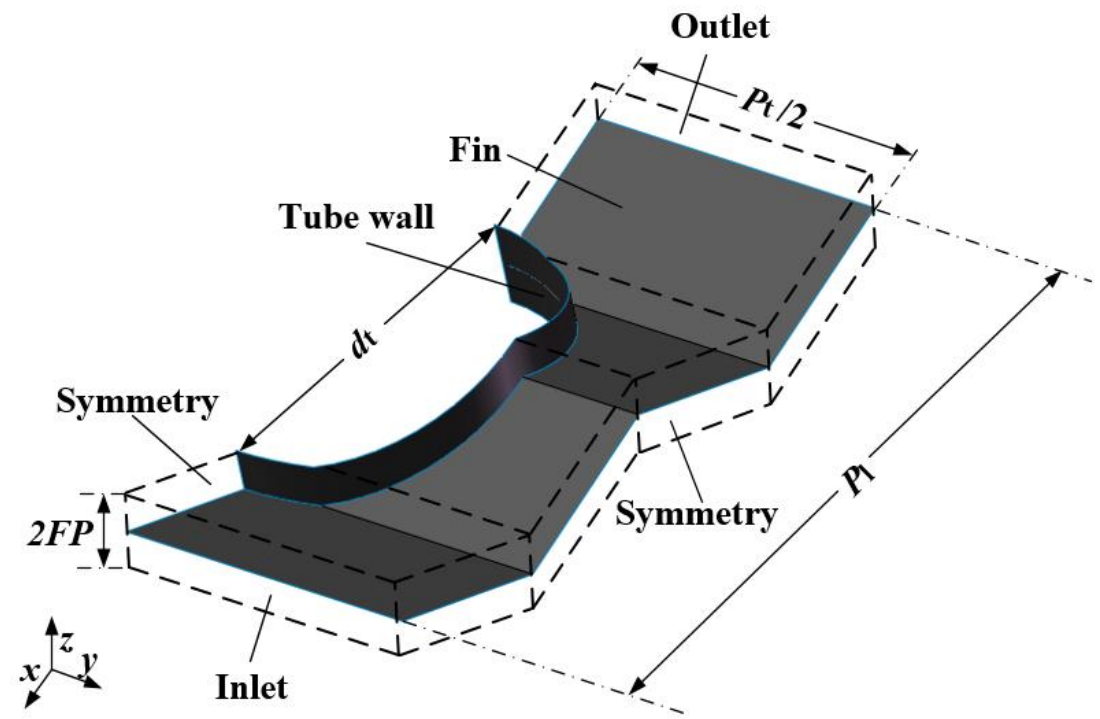

(a) Simulation domain of wavy fin-and-tube heat exchanger

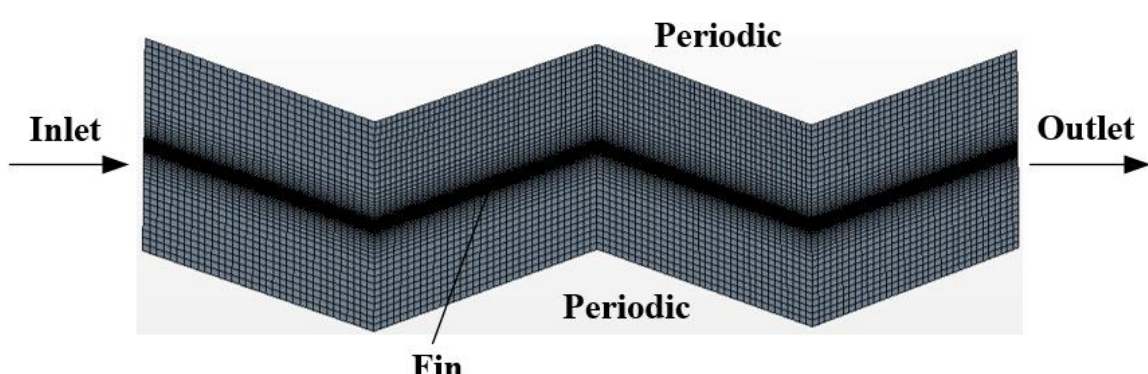

(b) Computational grids on the front view

Fig. 6. Simulation domain and computational grids. 


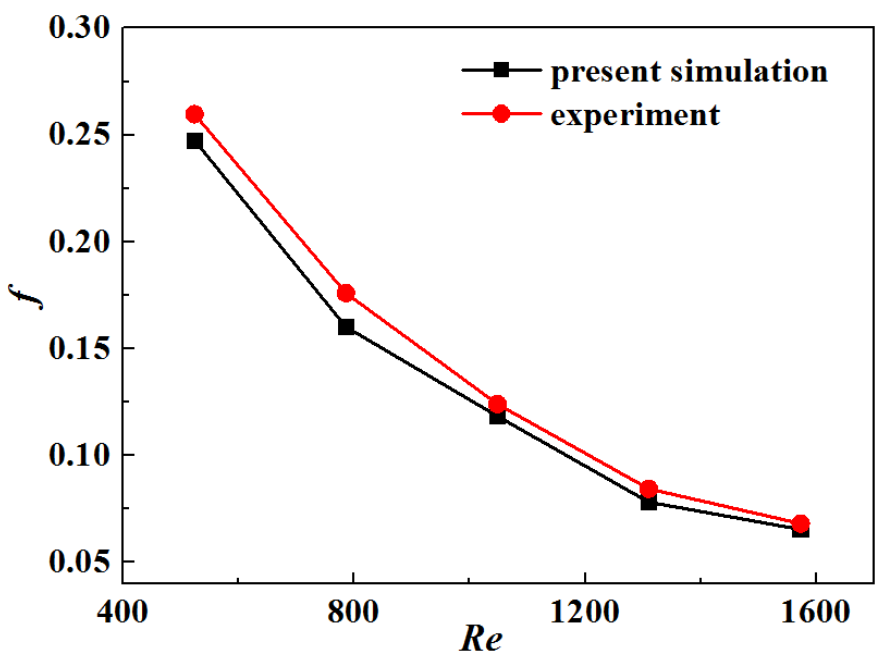

Fig. 7. Comparison of friction factor $f$ between experimental correlations (Wang et al., 2002) and the present simulations. 


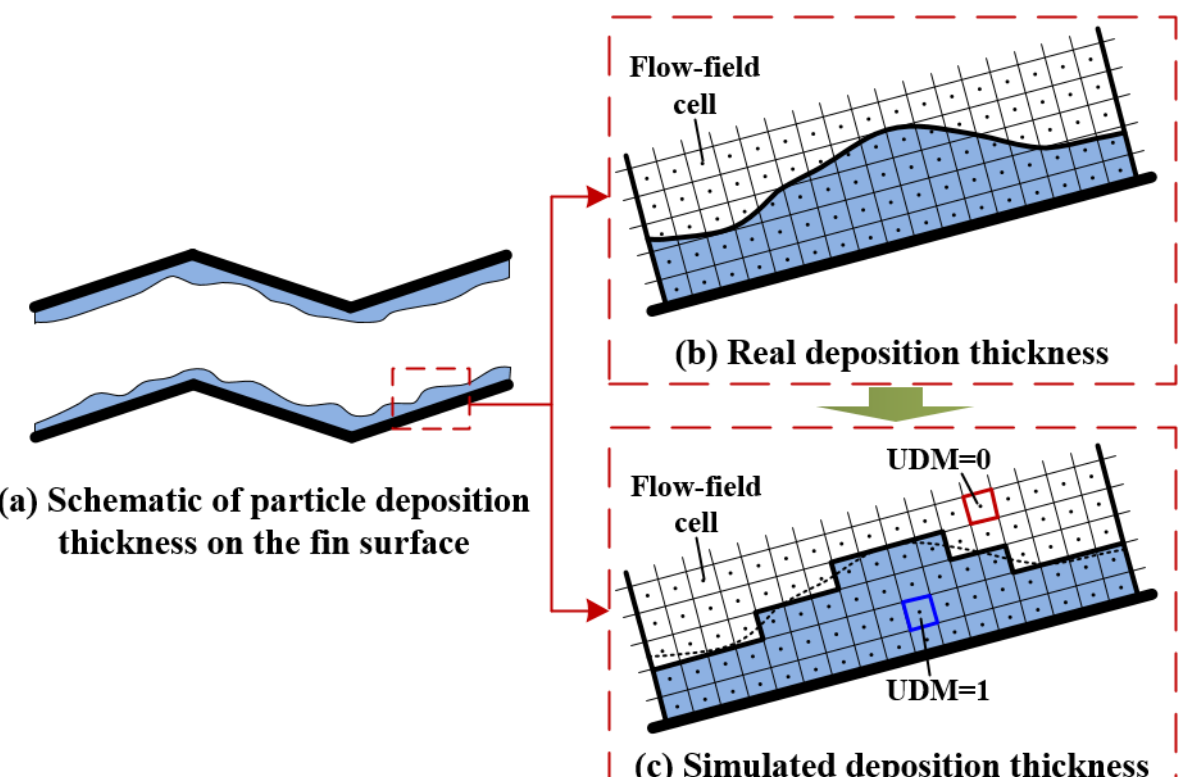

(c) Simulated deposition thickness

Fig. 8. Display method of particle deposition thickness. 


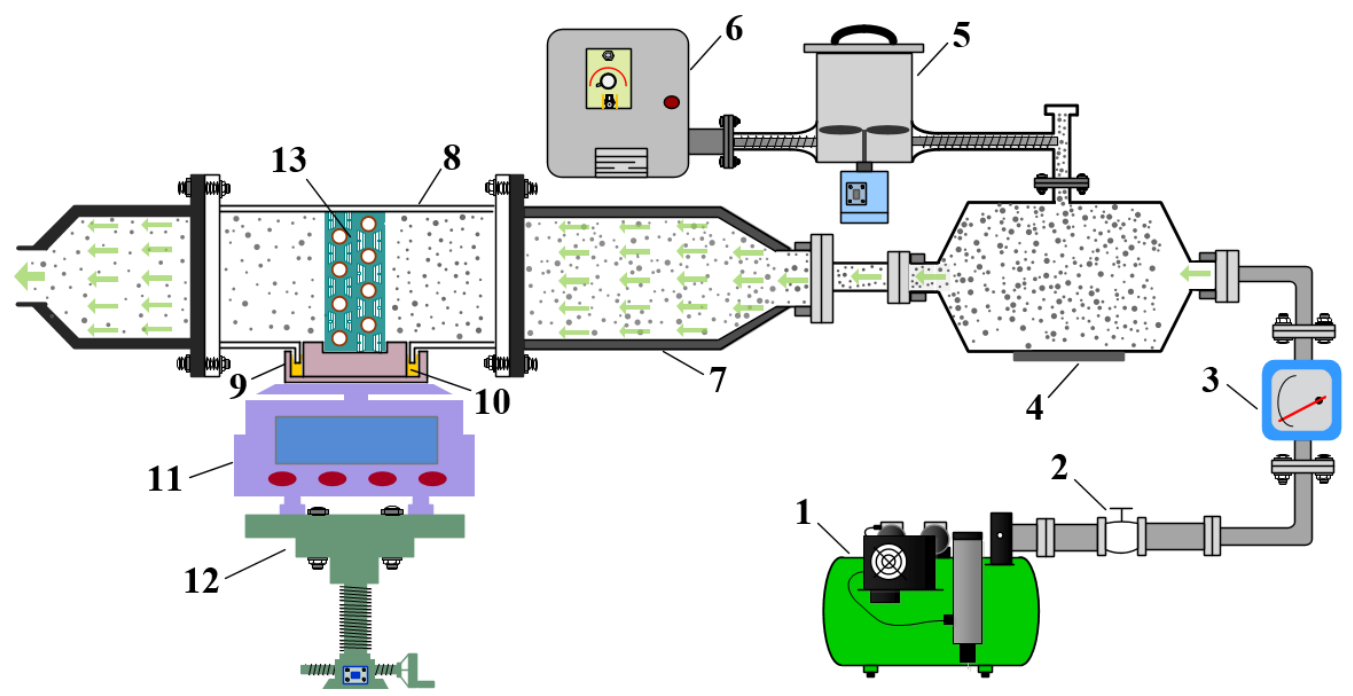

1- Air compressor, 2- Flow regulating valve, 3- Volume flow meter, 4- Mixing box,

5- Screw feeder, 6- Control cabinet, 7- Wind tunnel, 8- Plexiglass cover, 9- Tray,

10- Sponge, 11- Analytical balance, 12- Lifter, 13- Test sample

Fig. 9. Schematic of experimental rig. 


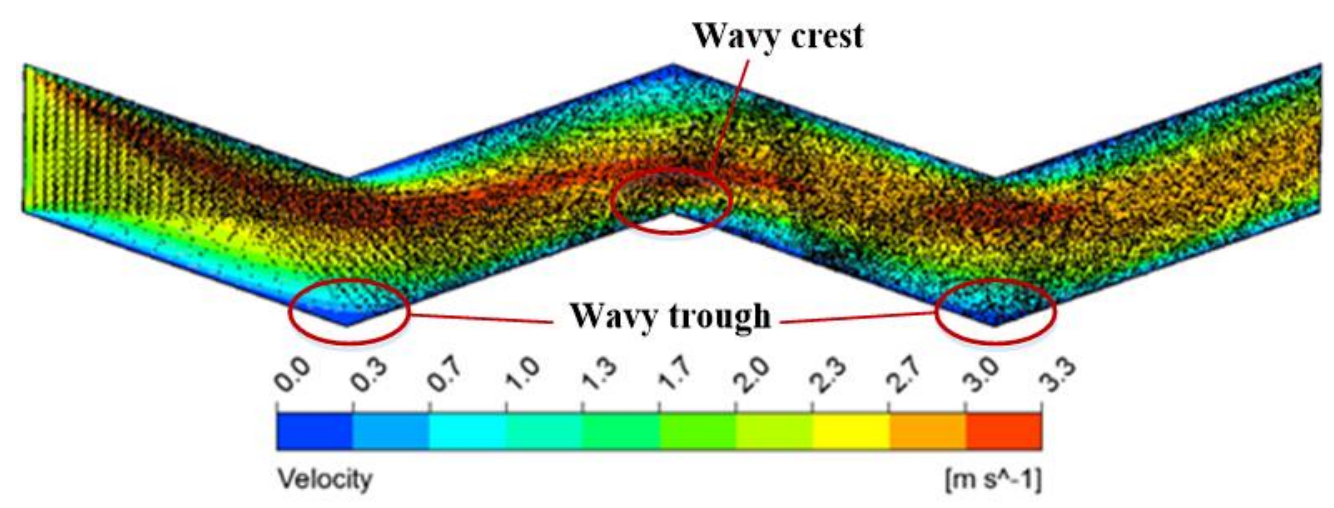

Fig. 10. Velocity contour and particle field distribution between wavy fins. 

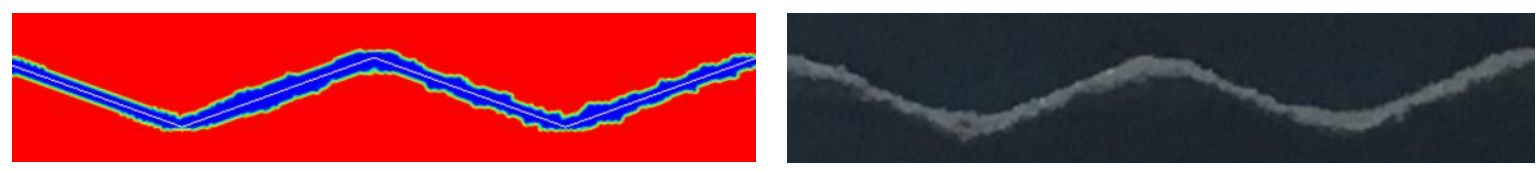

(a) $10 \mathrm{~min}$
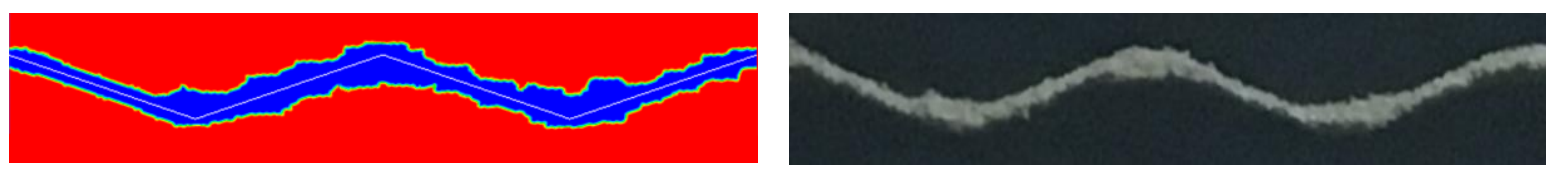

(b) $30 \mathrm{~min}$
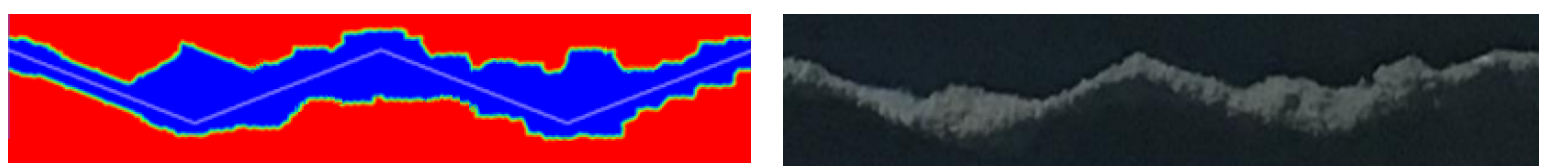

(c) $60 \mathrm{~min}$

Fig. 11. Comparison of predicted particle distributions and experimental images at different time. 


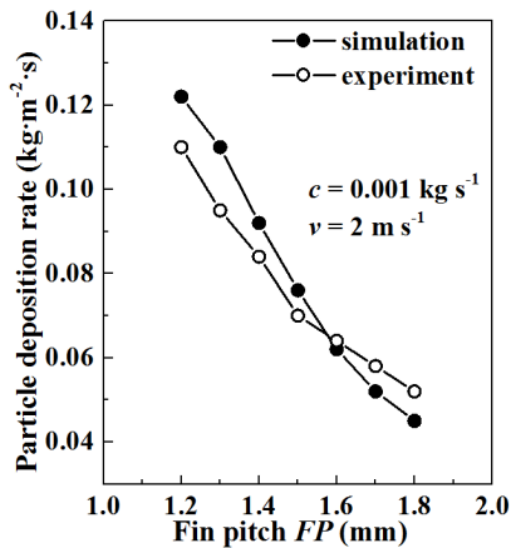

(a) Effect of fin pitch

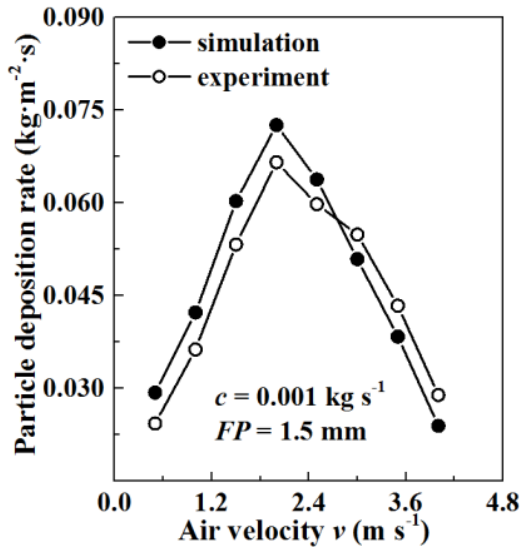

(b) Effect of air velocity

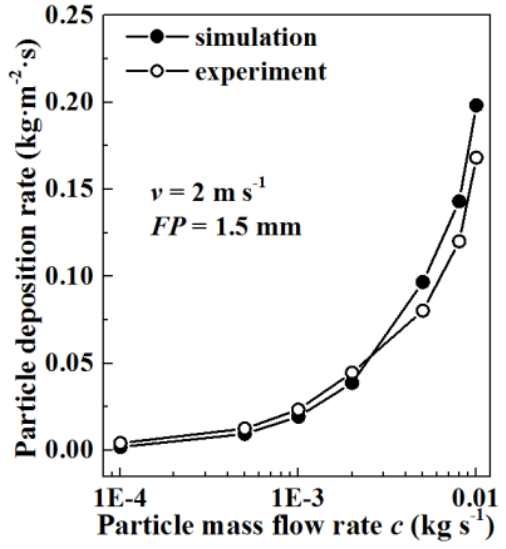

(c) Effect of particle mass flow

rate

Fig. 12. Comparisons of particle deposition rate between predicted and experimental results. 


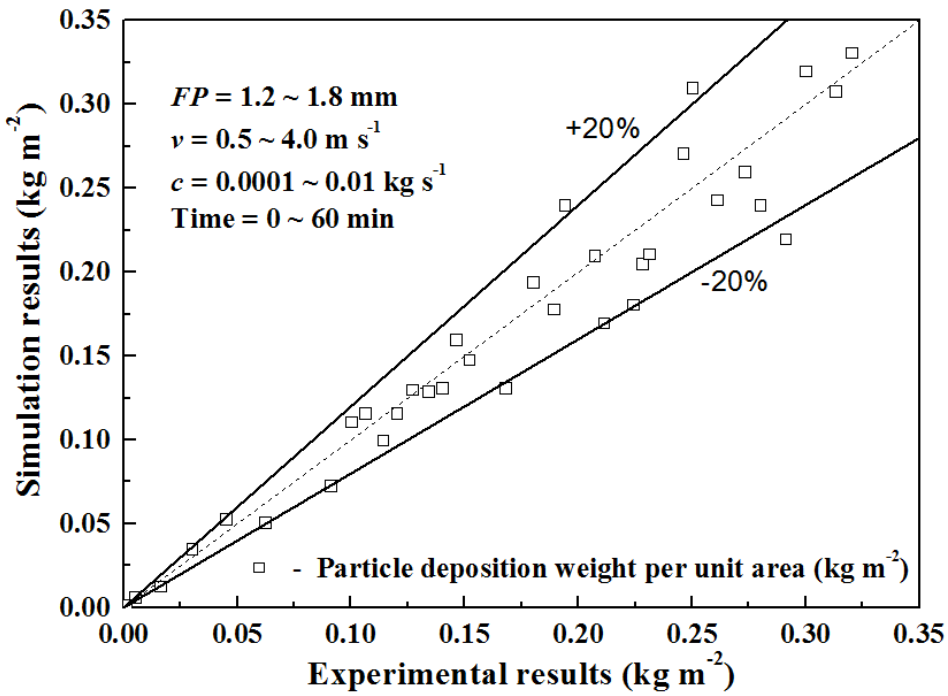

Fig. 13. Comparison between the simulation results and experimental data of particle deposition weight per unit area. 


\section{Table captions}

Table 1 The physical properties of particle.

Table 2 Geometric details of test sample. 
Table 1 The physical properties of particle.

\begin{tabular}{cccccc}
\hline $\begin{array}{c}\text { Density, } \rho \\
\left(\mathrm{kg} \mathrm{m}^{-3}\right)\end{array}$ & $\begin{array}{c}\text { Diameter, } d_{\mathrm{p}} \\
(\mathrm{m})\end{array}$ & $\begin{array}{c}\text { Equivalent Young's } \\
\text { modulus, } E^{*}(\mathrm{~Pa})\end{array}$ & $\begin{array}{c}\text { Surface energy, } \\
\zeta\left(\mathrm{J} \mathrm{m}^{-2}\right)\end{array}$ & $\begin{array}{c}\text { Effective shear } \\
\text { modulus, } G^{*}(\mathrm{~Pa})\end{array}$ & $\begin{array}{c}\text { Elastic load } \\
\text { limit, y }(\mathrm{N})\end{array}$ \\
\hline 2250 & $5 \times 10^{-5}$ & $3.8 \times 10^{10}$ & 0.3 & $7.6 \times 10^{9}$ & $2.65 \times 10^{8}$ \\
\hline
\end{tabular}


Table 2 Geometric details of test sample.

\begin{tabular}{ccccccc}
\hline $\begin{array}{c}\text { Fin pitch } \\
(\mathrm{mm})\end{array}$ & $\begin{array}{c}\text { Tube pitch } \\
(\text { transverse } / \mathrm{mm}) \times \\
(\text { longitudinal/mm })\end{array}$ & $\begin{array}{c}\text { Tube row } \\
\text { number }\end{array}$ & $\begin{array}{c}\text { Tube diameter } \\
(\mathrm{mm})\end{array}$ & $\begin{array}{c}\text { Size } \\
(\text { length } / \mathrm{mm}) \times(\text { width/mm }) \\
\times(\text { height/mm })\end{array}$ & $\begin{array}{c}\text { Wavy angle } \\
\left({ }^{\circ}\right)\end{array}$ & $\begin{array}{c}\text { Wavy height } \\
(\mathrm{mm})\end{array}$ \\
\hline $1.2 \sim 1.8$ & $21 * 12.7$ & 2 & 7 & $42 \times 50 \times 56$ & 20 & 1.6 \\
\hline
\end{tabular}

